\title{
DINÂMICA DE COBERTURA E USO DA TERRA E AS INTERVENÇÕES NA REDE DE DRENAGEM DA BACIA DO ARROIO SANGA FUNDA (RIO GRANDE DO SUL - BRASIL)
}

\author{
Ândrea Lenise de Oliveira LOPES ${ }^{1}$ \\ Rosangela Lurdes SPIRONELLO ${ }^{2}$ \\ Adriano Luís Heck SIMON³
}

\section{Resumo}

A bacia hidrográfica do Arroio Sanga Funda, localizada no perímetro urbano de Pelotas, Estado do Rio Grande do Sul é caracterizada por forte intervenção antrópica em sua dinâmica morfohidrográfica, com reflexos na organização espacial da rede de drenagem. Neste sentido, o presente trabalho foi desenvolvido com o objetivo de identificar e analisar as principais alterações na hidrografia da bacia do Arroio Sanga Funda decorrentes da dinâmica de cobertura e uso da terra em um período de 57 anos (1953 - 2010) afim de compreender a rede de drenagem como indicadora da magnitude das alterações antropogênicas desencadeadas pela dinâmica de ocupação do espaço. Foram elaborados dois mapas de cobertura e uso da terra e dois mapas da rede de drenagem referentes aos cenários do ano de 1953 e do ano 2010, a fim de representar e avaliar as transformações espaço-temporais ocorridas na área ao longo de período analisado. A análise dos produtos cartográficos possibilitou a constatação do alto grau de intervenção humana na rede de drenagem, com aumento na extensão de canais antropogênicos atrelados à expansão das áreas de cultivo de arroz irrigado e também de áreas urbanizadas.

Palavras- chave: Ocupação do espaço. Alterações ambientais. Antropogeomorfologia.

\footnotetext{
${ }^{1}$ Acadêmica do Programa de Pós-graduação em Geografia (Mestrado) - Universidade Federal de Pelotas (UFPEL). E-mail: lopes.andrea.geo@gmail.com

2 Departamento de Geografia e Programa de Pós-graduação em Geografia - Universidade Federal de Pelotas. E-mail: spironello.rosangela@gmail.com

3 Departamento de Geografia e Programa de Pós-graduação em Geografia - Universidade Federal de Pelotas. Endereço: Laboratório de Estudos Aplicados em Geografia Física (LEAGEF), Rua Alberto Rosa, 154, sala 105, Centro, Pelotas (RS- Brasil) 96010-770. (+55) 5332845500 (r. 212). E-mail: adriano.simon@ufpel.edu.br
} 


\section{Abstract}

\section{Land use/cover dynamics and the interventions in the drainage network of Sanga Funda watershed (Rio Grande do Sul - Brazil)}

Sanga Funda watershed, located in the urban area of Pelotas, Rio Grande do Sul State (Brazil) is characterized by a strong anthropic intervention in its morphohydrographic dynamics, with consequences in the drainage network spatial organization. In this sense, the present work was carried out with the purpose of identifying and analysing the main changes in the hydrography of Sanga Funda watershed resulting from land use/cover dynamics in a period of 57 years $(1953$ - 2010) in order to understand the drainage network as an indicator of the magnitude of anthropogenic changes launched by the dynamics of space occupation. Two land use/cover maps and two drainage network maps were elaborated referring to the scenarios in the year of 1953 and in the year of 2010, in order to represent and assess the temporal-spatial transformations which occurred in the area along the analyzed period. The analysis of the map products enabled the finding of a high degree of human intervention in the drainage network, with an increase in the extension of anthropogenic canals linked to the expansion of the areas of irrigated rice production as well as urbanized areas.

Key words: Space occupation. Environmental changes. Anthropogeomorphology.

\section{INTRODUÇÃO}

A configuração do espaço geográfico e sua organização ao longo da história humana exigiram uma constante e cada vez mais aprimorada transformação do meio natural a fim de manter as necessidades estruturais e funcionais do sistema socioeconômico. O controle dos elementos do meio físico-ambiental vem se desenvolvendo com esforços mínimos para o planejamento ou preocupação com a manutenção do equilíbrio dinâmico dos sistemas naturais, levando à quadros graves de degradação ambiental.

A dinâmica de cobertura e uso da terra atrelada ao processo de ocupação espacial pode ser considerada como o principal vetor das alterações nas características estruturais e processuais dos elementos do sistema físico-ambiental (LAMBIN et al., 1999), sobretudo naqueles que se encontram em contato direto com a ação do Homem como a cobertura vegetal, as formas do relevo e a rede de drenagem, ocasionando, por conseguinte, a aceleração, o retardamento e a extinção de alguns processos naturais como o escoamento linear em canais de drenagem fluviais e pluviais, a ocorrência de nascentes, a infiltração e o escoamento superficial e subsuperfícial (DREW, 1986; CASSETI, 1994; SIMON, 2007).

Neste sentido, a compreensão da dinâmica de cobertura e uso da terra adquire importância fundamental nas análises geográficas pois possibilita o monitoramento das áreas que estão sob intensa pressão ambiental, o diagnóstico das principais alterações desencadeadas pelo processo de ocupação e, ao mesmo tempo, a identificação das áreas que ainda podem ser preservadas e/ou recuperadas (SILVEIRA; CUNHA 2010; PASCHOAL et al. 2012; ZANATTA et al. 2015).

A dinâmica dos distintos usos da terra ocorre em consonância com o aperfeiçoamento das técnicas inerentes às práticas agropastoris e urbano-industriais, dentro de uma escala de tempo histórica, ou do Homem (SUETEGARAY; NUNES, 2001). Assim, níveis mais complexos de ocupação espacial só ocorrem a partir da imposição de mecanismos de controle que possibilitam usos intensivos dos elementos do sistema 
físico-ambiental. Estes mecanismos de controle antrópico se inserem no âmbito da Antropogeomorfologia (NIR, 1983; SZABÓ et al. 2010) e podem ser caracterizados pelo conjunto de morfologias e processos artificiais, análogos à dinâmica espaçotemporal geológica, que podem causar impactos irreversíveis nos sistemas físicoambientais e precisam ser compreendidos justamente para que possam ser considerados em ações de planejamento ambiental, recuperação de áreas degradadas e definição de áreas prioritárias para a proteção e conservação ambiental (PASCHOAL et al. 2012).

Ao considerar a relação entre a dinâmica do sistema socioeconômico e as alterações nas formas do relevo e na rede de drenagem em uma escala de tempo histórica, Nir (1983) propõe análises antropogeomorfológicas que contemplem períodos pré e pós significativa intervenção humana, destacando a necessidade de um cenário base para a avaliação das derivações antrópicas sobre a morfohidrografia. Assim, possibilita o desenvolvimento de análises sistêmicas nos estudos vinculados à geomorfologia antropogênica, pois conduz à compreensão da relação existente entre os elementos físico-ambientais e socioeconômicos ao longo do tempo, bem como as consequentes transformações espaciais decorrentes do controle humano sobre os processos naturais. Dessa maneira, a proposta do autor citado busca adequar a utilização de análises geomorfológicas elementares na abordagem das ações antrópicas ao longo do tempo e do espaço e para o dimensionamento das mudanças do meio físico por elas geradas (RODRIGUES, 2005; ZANATTA et al, 2015).

A partir destas considerações iniciais, este estudo foi desenvolvido com o objetivo de identificar e analisar as alterações ocorridas sobre a rede de drenagem da bacia hidrográfica do Arroio Sanga Funda (Pelotas - RS) e sua relação com a dinâmica de ocupação e uso da terra ocorrida dentro de um período de 57 anos (1953 2010). Procura-se, desta forma, compreender a rede de drenagem como indicadora da magnitude das alterações antropogênicas desencadeadas pelo processo de ocupação vinculado à dinâmica de cobertura e uso da terra.

\section{CARACTERIZAÇÃo DA ÁREA}

A bacia hidrográfica do Arroio Sanga Funda se localiza na porção nordeste do perímetro urbano de Pelotas e possui uma área aproximada de $31,38 \mathrm{Km}^{2}$ inserida entre as coordenadas UTM X: 380229.91m E 6489797.20m S e Y: $373060.36 \mathrm{~m}$ E $6497809.63 \mathrm{~m} \mathrm{~S}$ (Figura 1). A bacia é representativa sob o ponto de vista das alterações antropogênicas desencadeadas sobre a rede de drenagem em uma superfície de baixa altimetria localizada em zona de abrangência da Planície Lagunar Gaúcha.

De acordo com o Terceiro Plano Diretor da cidade de Pelotas (III PDP, 2008), a região onde se encontra a bacia hidrográfica do Arroio Sanga Funda é caracterizada como área rururbana "destinada às atividades de caráter agrosilvopastoril de baixo e médio grau de impacto em mínimo e pequeno portes, além das atividades de extração de areia e argila" (III PDP, 2008, p.83).

De acordo com o Mapa Geológico do Brasil (2004), organizado pelo CRPM (Serviço Geológico do Brasil), a área da bacia do Arroio Sanga Funda possui maior parte de seu território sobre domínios de depósitos da Planície Lagunar, formados por areia síltico-argilosa, mal selecionada, com laminação plano paralela incipiente. Já uma pequena parte da área de estudo, próxima à foz da bacia hidrográfica, se encontra sobre o domínio de depósitos praiais eólicos, formados por areia quartzosa fina, bem selecionada, retrabalhados pela dinâmica fluvial e por vezes soterrados por depósitos aluviais atuais. 

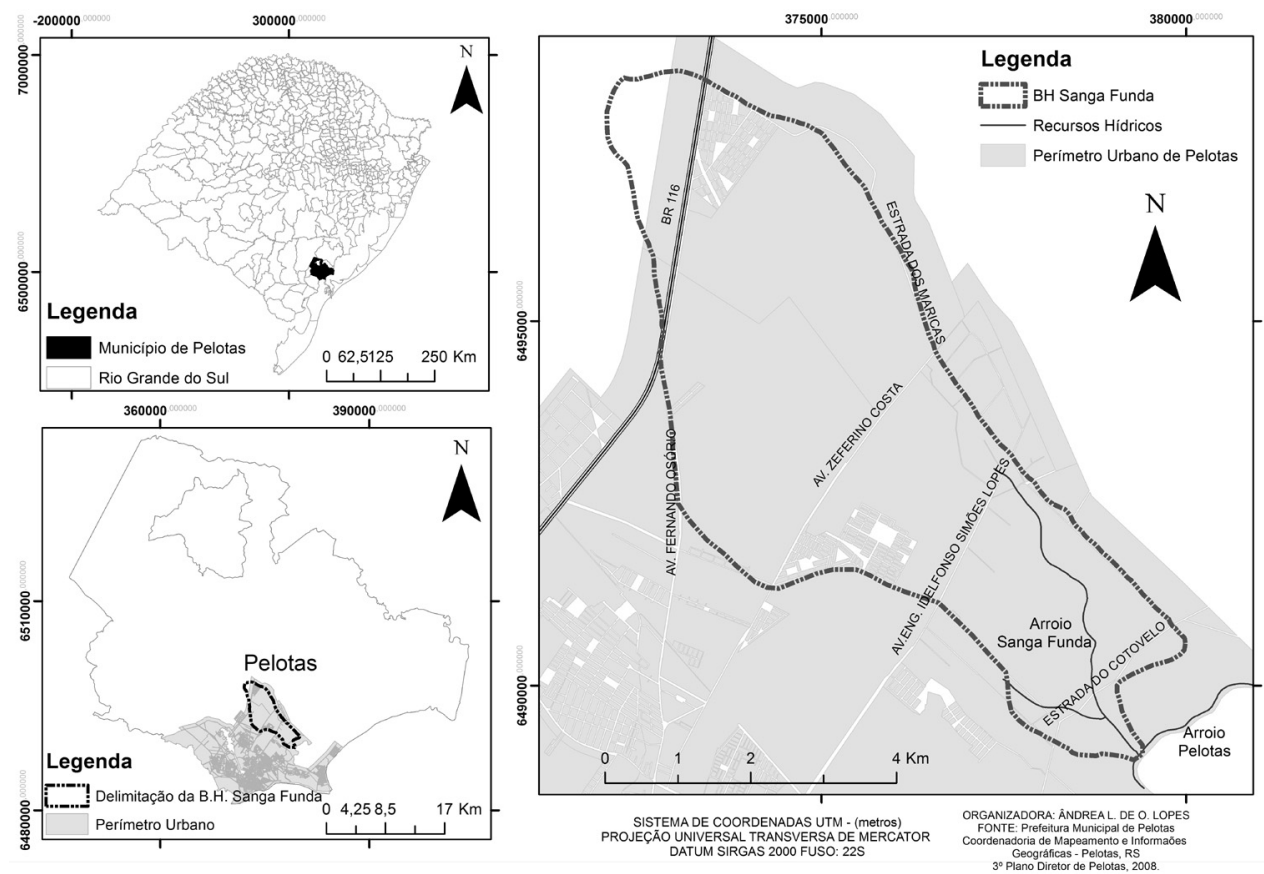

Figura 1 - Localização da Bacia Hidrográfica do Arroio Sanga Funda, Pelotas/RS

Por estar inserida em uma área de Planície Lagunar, o gradiente altimétrico da área é pouco significativo, não passando dos $20 \mathrm{~m}$, fato que torna complexo o estabelecimento dos limites com as bacias hidrográficas contíguas pois estes se encontram bastante descaracterizados pelas atividades agrícolas e estruturas urbanas consolidadas na área. Com relação aos aspectos geomorfológicos, a bacia do Arroio Sanga Funda está inserida na Planície Costeira Gaúcha que, segundo Rosa, (1986 p.36), "configura-se em uma paisagem plana e baixa, resultante da sedimentação recente e que corresponde à faixa contígua ao Canal São Gonçalo e à Laguna dos Patos". Nestas áreas predominam vertentes amplas com declividades de até $5 \%$ e os divisores de água apresentam pouca expressão na paisagem.

\section{ABORDAGEM METODOLÓGICA}

A orientação metodológica da presente pesquisa tem suas bases na Teoria Geral dos Sistemas aplicada à Geografia. A abordagem sistêmica se adequa aos estudos de bacias hidrográficas, pois as mesmas são consideradas sistemas abertos que recebem, transformam e liberam matéria e energia constantemente, além de integrarem em um mesmo espaço os elementos dos sistemas físico-ambiental e socioeconômico, viabilizando ações de planejamento e diagnóstico ambiental pautados no uso desta unidade natural (CHRISTOFOLETTI, 1979; BOTELHO; SILVA, 2004). 
No que diz respeito à complexidade estrutural do sistema aberto representado pela bacia hidrográfica do Arroio Sanga Funda, a mesma foi considerada enquanto sistema aberto controlado (CHRISTOFOLETTI, 1999). Neste tipo de sistema as atividades antrópicas caracterizadas pela dinâmica de cobertura e uso da terra conduzem, ao longo do tempo histórico, a mudanças operacionais na distribuição de energia e matéria que refletem no complexo primário dos elementos que se organizam espacialmente nesta unidade natural, sobretudo nas formas do relevo, na rede de drenagem e na cobertura vegetal, que são os elementos que se encontram em contato direto com a ação antrópica, possibilitando assim a aproximação entre os estudos em bacias hidrográficas e a abordagem antropogeomorfológica (CASSETI, 1994; SIMON, 2007; DREW, 1986).

\section{TÉCNICAS}

Para compreender e avaliar as alterações na rede de drenagem da bacia do Arroio Sanga Funda e sua relação com o processo de ocupação foram elaborados mapas que representam a hidrografia e as características de cobertura e uso da terra do referido sistema em dois cenários, 1953 e 2010, possibilitando a análise de alterações desencadeadas em um período de 57 anos.

Para a elaboração dos mapas da rede hidrográfica e de cobertura e uso da terra do ano de 1953 foram utilizadas 18 fotografias aéreas pancromáticas, em escala aproximada de 1:20.000 (faixas 435, 437 e 442), referentes ao do Levantamento Aerofotogramétrico do Município de Pelotas do ano 1953, digitalizadas e disponíveis em formato .tif, no acervo da biblioteca da Agência de Desenvolvimento da Lagoa Mirim (ALM/UFPEL).

As fotografias aéreas foram convertidas em anaglifos digitais tridimensionais que possibilitaram a análise da rede de drenagem a partir da utilização de óculos 3D. A geração dos anaglifos digitais tridimensionais ocorreu no ambiente do software livre StereoPhotoMaker, versão 4.41, de acordo com as orientações de Souza (2012) e Silva et al. (2013).

O georreferenciamento dos anaglifos ocorreu no ambiente do software ArcGis versão 10.0 (licença de uso do Laboratório de Estudos Aplicados em Geografia Física - UFPEL) sobre a Base Vetorial Contínua do Rio Grande do Sul (HASENACK; WEBER, 2006), que abrange as informações da carta topográfica Monte Bonito (SH.22-Y-D-IV1). Após o georreferenciamento dos anaglifos ocorreu a delimitação da bacia hidrográfica do Arroio Sanga Funda.

Para a elaboração dos mapas da rede hidrográfica e de cobertura e uso da terra do ano de 2010 foi utilizada a imagem orbital do sensor AVNIR-2 (Advanced Visible and Near Infrared Radiometer type 2), componente do sistema ALOS (Advanced Land Observing Satellite), com resolução espacial de $10 \mathrm{~m}$, referente ao ano de 2010, disponível no Laboratório de Estudos Aplicados em Geografia Física (LEAGEF- UFPEL).

O AVNIR-2 é um radiômetro que opera nas regiões do visível e infravermelho próximo, e foi desenvolvido para mapeamentos temáticos em escalas de até 1:50.000, com ênfase em uso e cobertura das terras. As imagens derivadas deste sensor tem sido comumente utilizadas para observação tanto da área continental, quanto de áreas costeiras, fornecendo resultados satisfatórios para o monitoramento ambiental e mapeamento de uso e cobertura da terra.

O sistema de classificação adotado para a elaboração dos mapas de cobertura e uso da terra dos anos de 1953 e 2010 seguiu as orientações do Manual Técnico de 
Uso da Terra do IBGE (2013). O quadro 1 apresenta as principais coberturas e usos identificados na área, bem como a composição RGB indicada pelo manual técnico. Entretanto, para fins de publicação, no presente artigo a variável visual cor foi substituída pelas variáveis valor e granulação. Em ambos os mapas o conceito atribuído foi o de diversidade, e a variável perceptiva escolhida é a seletiva, pois é possível selecionar elementos distintos. (MARTINELLI, 2014).

\section{Quadro1 - Classes de Usos e Coberturas da Terra, IBGE (2013)}

\begin{tabular}{|c|c|c|}
\hline $\begin{array}{c}\text { Sistema de Classificação } \\
\text { IBGE } 2013\end{array}$ & $\begin{array}{l}\text { Classe de uso e } \\
\text { cobertura da terra }\end{array}$ & $\begin{array}{c}\text { Cores por } \\
\text { temas }\end{array}$ \\
\hline \multirow{3}{*}{ Áreas antrópicas não agrícolas } & Área Urbanizada & $\begin{array}{l}R=255 \\
G=168 \\
B=192\end{array}$ \\
\hline & Áreas de Transição* & $\begin{array}{l}\mathrm{R}=178 \\
\mathrm{G}=178 \\
\mathrm{~B}=178\end{array}$ \\
\hline & Áreas de Mineração & $\begin{array}{l}R=173 \\
G=137 \\
B=205\end{array}$ \\
\hline \multirow{4}{*}{ Áreas antrópicas agrícolas } & Arroz Irrigado & $\begin{array}{l}R=255 \\
G=170 \\
B=000\end{array}$ \\
\hline & Pastagem & $\begin{array}{l}R=205 \\
G=137 \\
B=000\end{array}$ \\
\hline & Silvicultura & $\begin{array}{l}R=205 \\
G=173 \\
B=000\end{array}$ \\
\hline & Demais Culturas Temporárias & $\begin{array}{l}R=255 \\
G=255 \\
B=000\end{array}$ \\
\hline \multirow{2}{*}{$\begin{array}{l}\text { Áreas de vegetação natural e } \\
\text { coberturas da terra regionais }\end{array}$} & Florestal & $\begin{array}{l}R=115 \\
G=168 \\
B=000\end{array}$ \\
\hline & Campos Úmidos & $\begin{array}{l}\mathrm{R}=250 \\
\mathrm{G}=233 \\
\mathrm{~B}=190\end{array}$ \\
\hline Água & Corpos de Água Continentais & $\begin{array}{l}R=235 \\
G=255 \\
B=255\end{array}$ \\
\hline
\end{tabular}

*Adaptado devido a não adequação de inserção da categoria Áreas de Transição na classificação proposta pelo IBGE (2013). Fonte: Adaptado de IBGE (2013).

A elaboração dos mapas da rede hidrográfica dos cenários de 1953 e 2010 ocorreu a partir da identificação dos canais fluviais localizados em compartimentos de fundo de vale com perfil transversal plano, canais fluviais localizados em compartimentos de fundo de vale com perfil transversal em " $\mathrm{V}$ ", canais pluviais e canais antropogênicos, resultantes da ação antrópica a partir a ampliação de lavouras de arroz irrigado ou da expansão de espaços urbanos ou de mineração. 
Trabalhos de campo foram realizados ao longo dos anos de 2013 e 2014. Em 2013 ocorreram no intuito de reconhecer a área em estudo, compreender os limites da bacia hidrográfica - uma vez que os mesmos foram bastante descaracterizados pela ação antrópica - e para a identificar as particularidades dos tipos de coberturas, usos da terra e feições hidrográficas mapeadas no cenário mais atual. Ao longo de 2014 os trabalhos de campo ocorreram no sentido de contribuir para a constatação e atualização das informações espaciais dos mapas de cobertura e uso da terra e hidrográficos do cenário de 2010.

\section{DINÂMICA DE COBERTURA E USO DA TERRA NA BACIA HIDROGRÁFICA DO ARROIO SANGA FUNDA (1953 - 2010)}

As figuras 2 e 3 possibilitam uma análise da dinâmica de cobertura e uso da terra na área em estudo e revelam uma conjuntura onde as formações vegetais naturais ocupam um papel coadjuvante enquanto as práticas antrópicas caracterizadas pelo uso da terra predominam. Esta situação denota um processo de ocupação antigo onde mesmo a análise de um cenário da década de 1950 não é capaz de apreender as características espaciais das coberturas vegetais originais uma vez que usos bem consolidados e típicos das atividades econômicas chave do município de Pelotas (pecuária e cultivo de arroz irrigado) já predominam neste cenário inicial. Tal conjuntura também ocorre justamente pela localização da bacia hidrográfica em uma região periférica do perímetro urbano de Pelotas onde se sobressaem usos atrelados à área urbana consolidada ou à expansão urbana, lavras de mineração de argila e lavouras de arroz irrigado. Na figura 2 é possível ainda verificar o aumento da rede viária (arruamentos e vias de acesso secundárias) que atuaram de forma decisiva na redução das coberturas da terra e no aumento e segmentação dos tipos de usos da terra na bacia do Arroio Sanga Funda.

Dentre as classes de cobertura e uso da terra que tiveram sua área reduzida encontram-se as áreas de transição, as áreas de pastagem, as áreas de silvicultura e as áreas úmidas. Em contrapartida, as lavouras de arroz irrigado em conjunto com as demais culturas temporárias, a área urbanizada e as áreas de mineração tiveram os maiores aumentos de área (Figuras 2 e 3 ).

A expansão da área urbanizada na bacia do Arroio Sanga Funda se deu de forma expressiva ao longo dos 57 anos que abrangem a presente análise (Figuras 2 e 3 ), principalmente nas porções central e norte, acompanhando os principais eixos viários (avenidas, estradas secundárias e rodovias que atravessam a área da bacia). Em 1953 a superfície urbanizada possuía uma área de $0,16 \mathrm{~km}^{2}$ e se concentrava às margens da Avenida Fernando Osório (oeste da área em estudo) (Figura 2). Em 2010 as áreas urbanizadas passaram a ocupar $5,21 \mathrm{~km}^{2}$ (Figura 3 ), expandindo-se sobre superfícies que no cenário de 1953 foram reconhecidas e classificadas como áreas de transição e também sobre áreas de pastagem. 


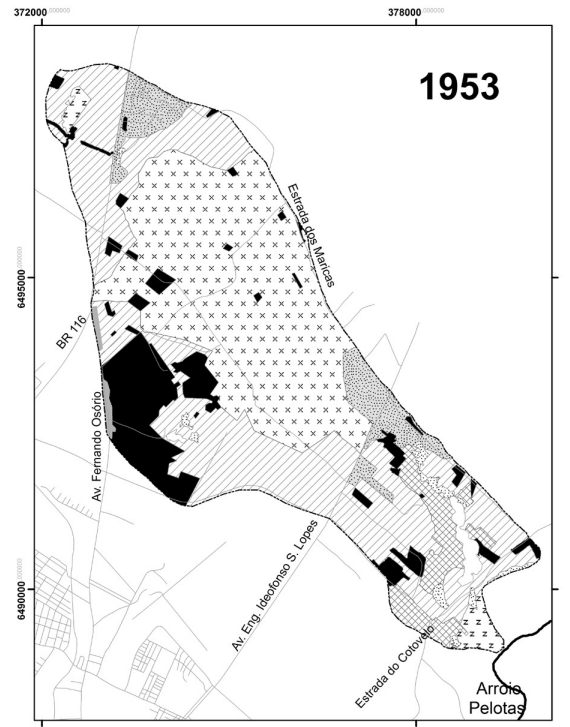

LEGENDA
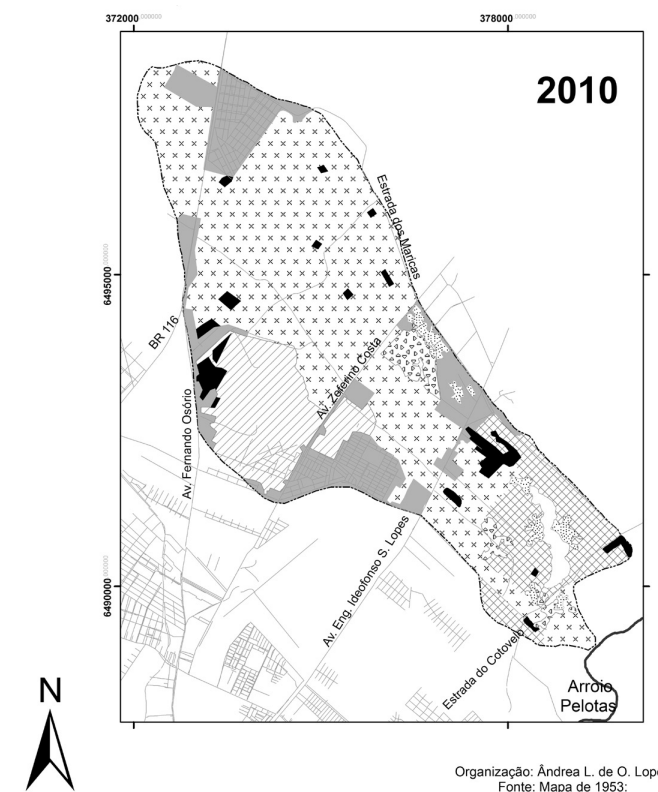

Organizaçẵo: Åndrea L. de O. Lopes Fonte: Mapa de 1953: Fotografias aéreas do ano de 1953 Escala 1:20.000 Faixas 435,437,442 18 imagens - ALM - UFPE

Convensões Cartográficas Convensões Temáticas

Delimitação da Bacia

Finestal

z $z$ Campos Úmidos

Projeção Universal Transversa de Mercator Mapa de 2010:

Resolução espacial de 10 metros
Anaselos Ano de 2010 - Leagef - Ufpel

Figura 2 - Coberturas e Usos da Terra da Bacia Hidrográfica do Arroio Sanga Funda Pelotas/RS (1953 - 2010)

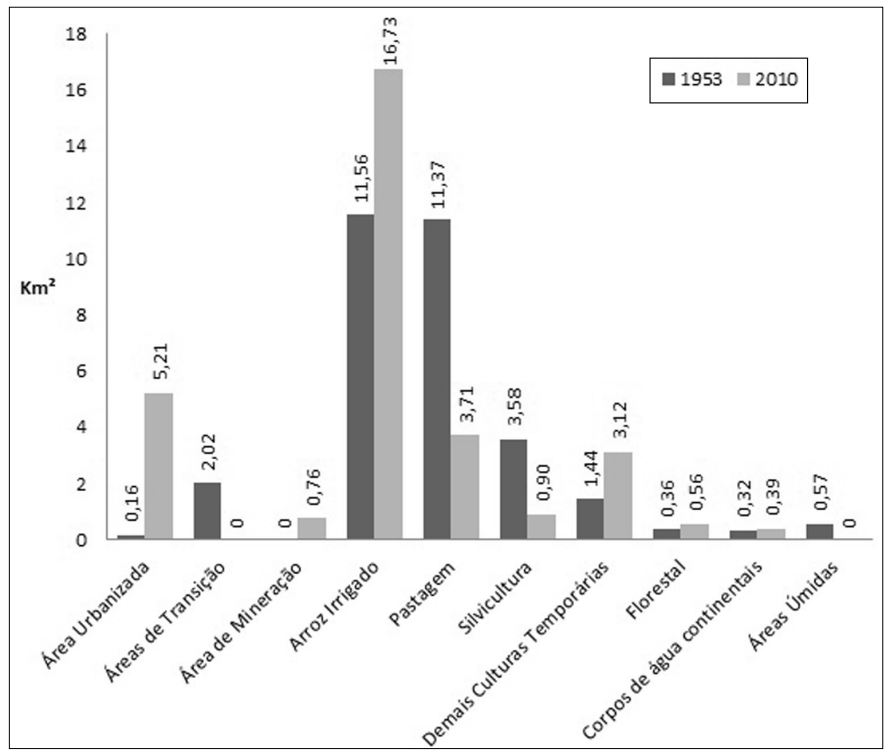

Figura 3 - Dinâmica das Coberturas e Usos da Terra na Bacia do Arroio Sanga Funda, Pelotas/RS entre os anos de 1953 e 2010 
As áreas de transição não são abrangidas pelo sistema de classificação das coberturas e usos da terra do IBGE (2013) e foram identificadas e classificadas de acordo com uma adaptação que incluiu as orientações da proposta de Anderson et al. (1979). O autor citado explica que as áreas de transição são aquelas que se caracterizam pela falta de informações concisas de sensoriamento remoto que tornem possível ao intérprete predizer, com segurança, o uso futuro ou discernir o uso passado. Tudo que pode ser realmente determinado, em tais situações, é que uma transição se encontra em processo e no caso da bacia do Arroio Sanga Funda, a transição em curso no cenário de 1953 diz respeito à conversão de usos agrícolas (pequenas propriedades de agricultura familiar e produção de hortifrutigranjeiros) para superfícies com ocupação mais adensada e malha viária mais bem consolidada.

Superfícies ocupadas por pastagens, no cenário de 1953, representam duas conjunturas distintas de redução de área ocupada, conforme diagnosticado no cenário de 2010 (Figura 2): no primeiro caso, referem-se à granjas, sítios ou estâncias que foram absorvidas pela expansão urbana, a partir de loteamentos que originaram bairros de periferia como Getúlio Vargas, Pestano e Vila Princesa (porções sudoeste e norte da Figura 2); no segundo caso, as áreas destinadas à pecuária foram convertidas em lavouras de arroz irrigado, situação que se estabeleceu a partir das décadas de 1960 e 1970, com o declínio final do ciclo do charque e a expansão da indústria de alimentos em Pelotas.

O arroz irrigado é o uso que apresenta maior representatividade espacial nos dois cenários analisados. Apesar de pertencer à classe das culturas temporárias, de acordo com o IBGE (2013), as áreas de arroz irrigado foram analisadas de forma independente em função das significativas alterações provocadas pelas canchas de cultivo sobre a morfologia e a rede de drenagem. Neste sentido cabe destacar que a bacia do Arroio Sanga Funda é representativa da maior parte das bacias hidrográficas que se encontram no mesmo contexto físico-ambiental regional (áreas planas, com superfícies mal ou muito mal drenadas inseridas na Planície Lagunar Gaúcha), onde a expansão das lavouras de arroz irrigado e as alterações morfohidrográficas atreladas a este cultivo agrícola atuam de forma drástica na configuração espacial dos elementos físico-ambientais das bacias hidrográficas.

Os mapas de cobertura e uso da terra (Figura 2) indicam que mesmo em 1953 a atividade agrícola destinada ao cultivo de arroz já se fazia presente na bacia hidrográfica do Arroio Sanga Funda, entretanto em 2010 verifica-se a expansão e predomínio desta prática agrícola, inclusive sobre usos da terra característicos da região como as pastagens atreladas a atividade pecuária.

Para o cultivo de arroz irrigado são utilizadas técnicas que promovem o aplainamento da superfície, deixando-a nivelada e descaracterizando a topografia e o relevo local (Figura 4). Simon (2007) afirma que o impacto e as alterações da atividade orizícola sobre o escoamento superficial e subsuperficial começam a partir do momento em que se inicia a contenção da água nas canchas de cultivo e o retardamento de sua chegada ao leito dos canais fluviais. O autor explica ainda que as lavouras de arroz irrigado conduzem a uma homogeneidade, nivelamento e compactação das superfícies - evitando perdas de água nas canchas de cultivo comprovando assim a eficiência de técnicas mecanizadas na consolidação de feições antrópicas que controlam a morfohidrodinâmica.

As lavouras de arroz necessitam de irrigação constante, causando uma demanda significativa por água, tornando-se um problema em épocas de pouca precipitação. Para suprir esta demanda é comum em tal atividade a construção de reservatórios artificiais onde a água é captada para a irrigação das lavouras. 


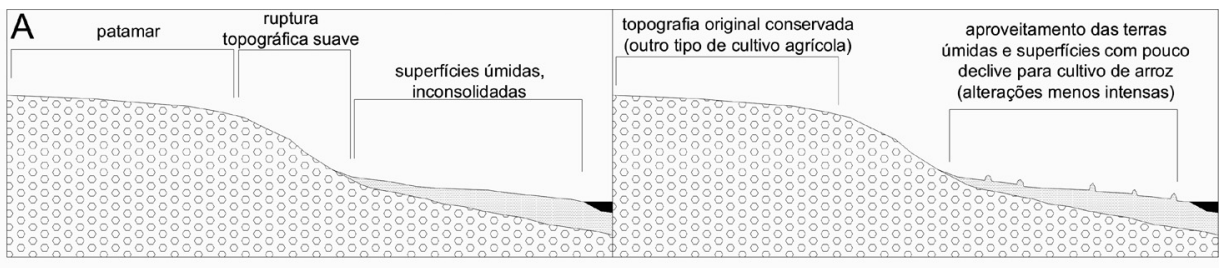

B

ruptura topográfica suave
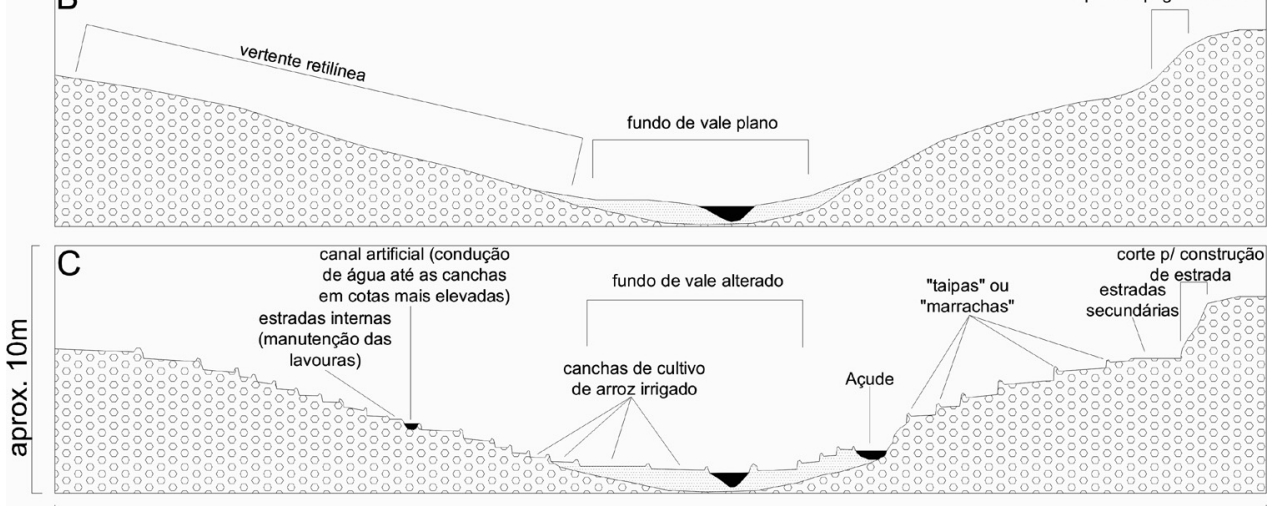

aprox. $1000 \mathrm{~m}$

Figura 4 - Características das alterações morfohidrográficas desencadeadas pelas lavouras de arroz irrigado:(A) superfície destinada ao cultivo do arroz irrigado que sofre alterações menos intensas, pois os caimentos topográficos e a drenagem natural são aproveitados; ( $B$ e C) as técnicas agrícolas envolvidas nesse segundo tipo de lavouras de arroz contam com a utilização de maquinário pesado na preparação das canchas de cultivo e na construção das ondulações de contenção de água. As intervenções na morfologia original ocorrem no sentido de reduzir ao máximo o desnível entre as canchas, segmentando o terreno em quantas partes forem necessárias, dependendo da inclinação e da irregularidade da vertente

Fonte: Adaptado de Simon (2007).

Assim como o arroz irrigado, as demais culturas temporárias também tiveram aumento de área, sobretudo nas proximidades da vila Sanga Funda (baixa bacia). Cabe destacar que na área em estudo as demais culturas temporárias são caracterizadas pelo plantio de hortifrutigranjeiros que abastecem o mercado consumidor de Pelotas e região.

As áreas úmidas inseridas no contexto da bacia do Arroio Sanga Funda foram verificadas apenas no cenário de 1953, tendo sido convertidas para o cultivo de arroz irrigado no cenário de 2010 (Figuras 2 e 3). As áreas úmidas são importantes pela elevada complexidade biológica e por atuarem como agente regulador dos sistemas flúvio-lacustres que ocorrem na Planície Lagunar Gaúcha. Porém, são as áreas mais visadas para a expansão das canchas de cultivo de arroz irrigado. Apesar de os dados espaciais dos mapeamentos de cobertura e uso da terra evidenciarem uma tímida ocorrência das áreas úmidas na baixa bacia do Arroio Sanga Funda no cenário de 1953, presume-se que estas superfícies possuíam maior representatividade espacial 
em décadas anteriores, sobretudo nas margens de canais fluviais localizados em compartimentos de fundo de vale com perfil transversal plano e em concavidades de vertentes, uma vez que este é o comportamento típico destas formações vegetais em área de transição dos biomas Pampa e Mata Atlântica na Planície Lagunar Gaúcha.

De acordo com a Associação dos Ceramistas de Pelotas (ACERPEL) as atividades de mineração de argila no Bairro Sanga Funda iniciaram há 40 anos, o que explica o fato deste esse uso não ter sido identificado no cenário de 1953 (Figura 2). A lavra de argila localizada no Bairro Sanga Funda é aberta e possui potencial poluidor de nível médio, sendo que em campo foi verificado que a bancada de lavra varia de 3 a 5 metros de altura. A deposição dos rejeitos oriundos da extração está sendo mantida dentro da área licenciada e delimitada para tal e existe um controle para que sejam evitados os processos de erosão e deslizamentos nas pilhas de estocagem.

Tal material servirá para cobrir as valas no momento da recuperação do local. Segundo informações levantadas em campo, no local de extração de argila é realizado um esquema de drenagem para que a água do escoamento superficial seja emitida diretamente ao Arroio Sanga Funda. Os principais impactos da atividade de mineração na área em estudo se referem à alteração na configuração das formas do relevo em escala local, confluindo para modificações no escoamento superficial e na alteração das concavidades de vertentes que sustentam o escoamento pluvial e que acabam se irradiando para as porções à jusante das lavras de extração de argila.

Cabe salientar ainda o impacto indireto causado pela mineração, como por exemplo, a fumaça emitida pelos fornos de fabricação de tijolos, junto às olarias que se concentram no Bairro Sanga Funda, próximas das lavras de extração de argila e também de casas, estabelecimentos comerciais e públicos, bem como de áreas de cultivo de hortifrutigranjeiros.

O aumento das áreas florestais na bacia hidrográfica do Arroio Sangra Funda (Figuras 2 e 3) embora muito tímido, se deu prioritariamente em função de ações de reflorestamento com espécies nativas atreladas à recuperação de áreas degradadas, fato que explica sua localização próxima às áreas de mineração. Em campo pode-se constatar que a ampliação das áreas florestais também se deu com a finalidade de conter processos erosivos próximos ao reservatório de água na baixa bacia.

\section{ALTERAÇÕES HIDROGRÁFICAS VINCULADAS A DINÂMICA DE COBERTURA E USO DA TERRA}

A dinâmica de cobertura e uso da terra ocorrida na bacia do Arroio Sanga Funda foi responsável por significativas alterações da rede de drenagem. A análise dos cenários de 1953 e 2010 (Figura 5) evidencia a ocorrência de retilinizações, transposições, alteração da dinâmica erosiva/deposicional e soterramentos/extinções de canais fluviais, pluviais e nascentes ao longo de toda a bacia hidrográfica. Os mapas da rede de drenagem revelam as modificações impostas ao sistema aberto em questão, a partir dos mecanismos de controle peculiares a cada um dos tipos de usos da terra verificados na área em estudo e que foram sendo impostos à hidrografia, alterando sua configuração espacial que passou a responder pela lógica de tempo histórica dos mecanismos antrópicos de controle estrutural e processual.

O quadro 2 permite uma avaliação das alterações desencadeadas na hidrografia da bacia do Arroio Sangra Funda, evidenciando as mudanças ocorridas nos diferentes tipos de canais entre os cenários de 1953 e 2010. 


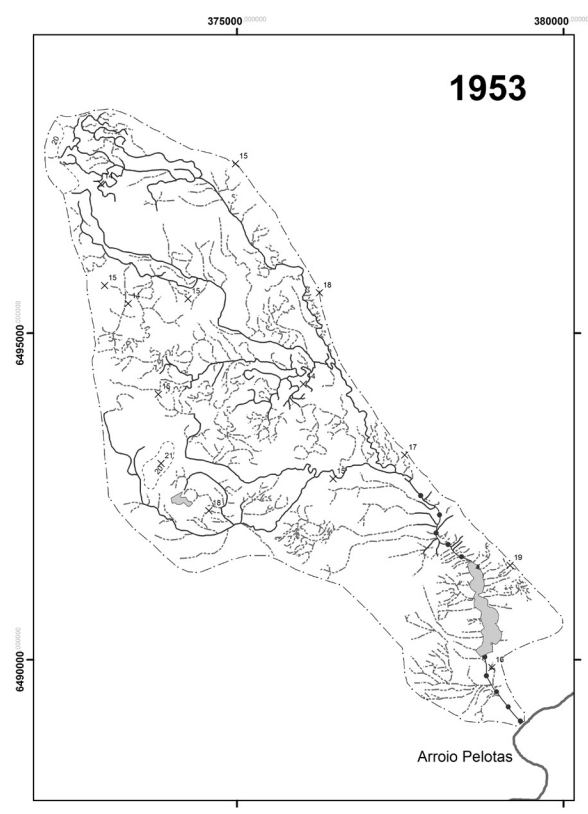

Legenda

$\times$ Pontos Cotados

- Curvas de Nivel

•. Canais Fluviais em Fundo "V"

Reservatório
-.-.-.- Canais Pluviais

+ Canais Antropizados
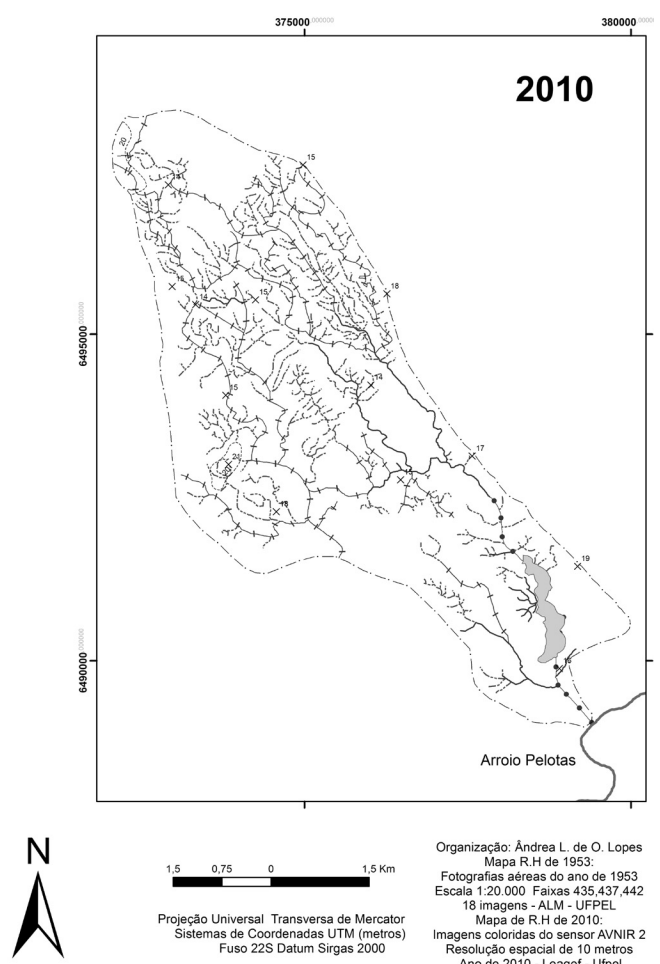

Organização: Ândrea L. de O. Lopes Fotograpa R.H de 1953: 1953 Escala 1:20.000 Faixas 435,437,442 18 imagens - ALM - UFPEL Mapa de R.H de 2010: magens coloridas do sensor AVNIR Resoluçẫo espacial de 10 metro

Figura 5 - Rede Hidrográfica da Bacia do Arroio Sanga Funda, Pelotas/RS

\section{Quadro 2 - Extensão Linear dos segmentos de canais que compõe a rede de drenagem da Bacia Hidrográfica do Arroio Sanga Funda, Pelotas - RS (1953 - 2010)}

\begin{tabular}{|c|c|c|c|c|}
\hline Segmento de canal & $\begin{array}{c}1953 \\
\text { Extensão } \\
(\mathrm{km})\end{array}$ & $\begin{array}{c}\% \text { sobre } \\
\text { total de } \\
1953\end{array}$ & $\begin{array}{c}2010 \\
\text { Extensão } \\
(\mathrm{km})\end{array}$ & $\begin{array}{c}\% \text { sobre } \\
\text { total de } \\
2010\end{array}$ \\
\hline $\begin{array}{c}\text { Canais Fluviais em } \\
\text { compartimentos de fundo de vale } \\
\text { com perfil transversal em "V" }\end{array}$ & 4,27 & $2,13 \%$ & 3,24 & $2,15 \%$ \\
\hline $\begin{array}{c}\text { Canais Fluviais em } \\
\text { compartimentos de fundo de vale } \\
\text { com perfil transversal em Fundo } \\
\text { Plano }\end{array}$ & 53,45 & $26,70 \%$ & 15,54 & $10,30 \%$ \\
\hline Canais Antropogênicos & - & - & 42,36 & $28,07 \%$ \\
\hline Canais Pluviais & 142,49 & $71,17 \%$ & 89,74 & $59,48 \%$ \\
\hline Total & 200,21 & $100 \%$ & 150,88 & $100 \%$ \\
\hline
\end{tabular}

Fonte: Organizado pelos autores. 
A primeira questão que se observa a partir da análise da figura 5 e do quadro 2 é a diminuição da extensão total da rede de drenagem da bacia do Arroio Sanga Funda, incluindo os segmentos de canal fluvial e pluvial, diminuindo assim a sua densidade de drenagem. Os canais pluviais - linhas de escoamento alimentadas durante as precipitações e períodos próximos às precipitações, responsáveis pela recarga do lençol freático e pela manutenção da rede hidrográfica - tiveram as maiores alterações em sua extensão (Quadro 2).

Os canais pluviais foram considerados nesta análise pois diante das características geomorfológicas da área em estudo - relevo plano com vertentes pouco inclinadas e extensas, com ocorrência de poucos segmentos de canais fluviais - são importantes para compreender o comportamento do escoamento superficial que se desenvolve na bacia hidrográfica, e indicam aspetos importantes da configuração espacial das concavidades de vertentes onde se desenvolvem. A diminuição dos canais pluviais assinala ainda a alteração destas concavidades de vertentes a partir de aterramentos e aplainamentos de superfícies causados sobretudo pela expansão urbana e das lavouras de arroz irrigado, e que descaracterizaram estas linhas de escoamento.

Segmentos de canal fluvial situados em compartimentos de fundo de vale com perfil transversal em " $V$ " apresentaram as menores alterações ao longo dos 57 anos que abrangem a presente análise. A comparação entre as Figuras 2 e 5 evidencia que estes segmentos de canais fluviais são encontrados prioritariamente na baixa bacia do Arroio Sanga Funda, em área de influência de um reservatório de água. À montante deste reservatório se mantiveram, entre os cenários de 1953 e 2010, coberturas e usos da terra atrelados às florestas e silvicultura que possibilitaram a manutenção da morfologia destes fundos de vale e a preservação dos segmentos situados em compartimentos de fundo em " $V$ ". À jusante deste reservatório também se manteve o segmento de canal fluvial em compartimento de fundo de vale em " $V$ " possivelmente em decorrência do fluxo liberado pelo reservatório que atua na contínua incisão do talvegue, agindo, portanto, como mecanismo de controle do comportamento espacial deste segmento de canal.

Os segmentos de canal fluvial situados em compartimentos de fundo de vale com perfil transversal em "V" são bastante atípicos na configuração geomorfológica da Planície Lagunar Gaúcha e no caso da área em estudo podem ter se constituído em um período anterior à abrangência da presente análise, em função de ajustes vinculados à construção do reservatório situado na bacia do Arroio Sanga Funda.

Os canais fluviais situados em compartimento de fundo de vale com perfil transversal plano ocupavam, em 1953, 53,45\% da área em estudo, e em 2010 15,54\% (Quadro 2). A maior parte destes segmentos de canal fluvial tiveram suas áreas de captação ocupadas por usos da terra atrelados às lavouras de arroz irrigado e pelas áreas urbanas (Figuras 2 e 5). Nas porções norte e sudoeste da área em estudo a evolução das áreas urbanas soterrou muitos canais fluviais situados em compartimentos de fundo de vale com perfil transversal plano a partir da imposição de aterramentos antropogênicos, conforme verificado em campo.

Entretanto, as lavouras de arroz irrigado causaram as maiores alterações na configuração espacial dos canais fluviais situados em compartimentos de fundo de vale com perfil transversal plano, que foram controlados a partir de técnicas de retilinização e transposição a fim de abastecer as canchas de cultivo de arroz irrigado em períodos de plantio e drenar estes espaços agrícolas em épocas de maturação e colheita, criando morfologias específicas de canais fluviais caracterizados como canais antropogênicos.

Os canais antropogênicos inexistiam na área em estudo em 1953 e evoluíram em consonância com as técnicas de controle agrícola empregadas nas lavouras de arroz irrigado. Canais retilinizados e transpostos tiveram um aumento de $28 \%$ na 
bacia do Arroio Sanga Funda e também estão vinculados à expansão urbana uma vez que a abertura de linhas de escoamento artificiais é prática comum para a drenagem de superfícies planas onde são consolidados lotes urbanos regulares e irregulares. Nos espaços urbanizados estes canais antropogênicos são geralmente utilizados como local de emissão de esgoto doméstico, conforme constatado em trabalhos de campo.

Os canais antropogênicos não respeitam nenhuma lógica da configuração do relevo local. A rede caracterizada por este tipo de canal não possui nascentes ou foz e inexistem direções predominantes ou ângulos de conexão das bifurcações de canal. Estes canais rompem, inclusive, os limites naturais da bacia hidrográfica da bacia do Arroio Sanga Funda, conforme é possível perceber nos limites norte e sudoeste da área em estudo no cenário de 2010 (Figuras 2 e 5), evidenciando a presença do agente antrópico no controle deste sistema fluvial e na definição de morfologias antropogênicas que tornam complexa a gestão ambiental pautada nos limites da bacia hidrográfica.

\section{CONSIDERAÇÕES FINAIS}

Os mecanismos de controle antrópico vinculados aos distintos e complexos usos da terra que atuam na bacia hidrográfica do Arroio Sanga Funda foram responsáveis pelas rápidas alterações na hidrografia da área. A rede de drenagem se mostrou como um importante indicador quantitativo e qualitativo das alterações antropogênicas verificadas, possibilitanto a verificação de áreas-chave para a atuação de planos de recuperação de áreas degradadas e ações de planejamento ambiental, reforçando a atuação da abordagem antropogeomorfológica no estudo de bacias hidrográficas.

Diante do predomínio da análise de áreas densamente urbanizadas por parte dos estudos que possuem suas bases teóricas e metodológicas na Antropogeomorfologia, o presente estudo vem a contribuir, pois apresenta o relevante papel do homem como agente modificador da paisagem morfohidrográfica também em ambientes de transição entre usos da terra urbanos e rurais, com forte impacto das atividades de mineração.

Os resultados obtidos a partir da análise realizada na bacia hidrográfica do Arroio Sanga Funda evidenciam um conjunto de mecanismos de controle e alterações no sistema físico-ambiental que são característicos da maior parte das bacias hidrográficas que possuem nascentes na Planície Lagunar Gaúcha e deságuam na Laguna dos Patos. Assim, é imprescindível que estudos que abordem as alterações na rede de drenagem vinculadas à dinâmica de cobertura e uso da terra sejam realizados também nos sistemas fluviais contíguos a fim de que se possa obter um diagnóstico regional das alterações espaço-temporais nas unidades naturais que drenam para a Laguna dos Patos.

Por fim, cabe destacar que, apesar da análise realizada abranger um período significativo para a avaliação das alterações antropogênicas, verificou-se a ocorrência de usos da terra responsáveis pelas alterações morfohidrográficas num período anterior ao primeiro cenário analisado, evidenciando que a ação das técnicas de controle antrópico muitas vezes escapa das possibilidades de análise geográfica devido à não disponibilidade de materiais cartográficos de períodos pré intervenção e/ou perturbação do sistema físico-ambiental. 


\section{REFERÊNCIAS}

ANDERSON, J. R.; HARDY, E.E.; ROACH,J.T; WITMER, R.E. Sistema de classificação do uso da terra e do revestimento do solo para utilização com dados de sensoriamento remoto. RJ: IBGE, 1979. 78p.

BOTELHO, R. G. M. Planejamento Ambiental em Microbacia Hidrográfica. In.: GUERRA, A. J. T.; SILVA, A. S.; BOTELHO, R. G. M. (orgs.). Erosão e conservação dos solos - Conceitos, temas e aplicações. 6a Ed. Rio de Janeiro: Bertrand Brasil, 2010. (p. 269 - 300).

CASSETI, V. Elementos de Geomorfologia. Goiania: Editora da UFG, 1994. 137 p. CHRISTOFOLETTI, A. Análise de Sistemas em Geografia. São Paulo: Hucitec, 1979. $106 \mathrm{p}$.

CHRISTOFOlETtI, A. Modelagem de Sistemas Ambientais. São Paulo: Edgard Blüncher, 1999. 236 p.

DREW, D. Processos interativos Homem-Meio Ambiente. São Paulo: DIFEL, 1986. 206p.

HASENACK,W; WEBER, E. Base Cartográfica Vetorial Contínua do Rio Grande do Sul. Escala 1:250.000. Porto Alegre: UFRGS, Centro de Ecologia, 2006.

IBGE. Manual Técnico de Uso da Terra. 2 ed. Rio de Janeiro. 2013. Disponível em: <ftp://geoftp.ibge.gov.br/documentos/recursosnaturais/usodaterra/ manualusodaterra.pdf $>$

LAMBIN, E.F. et al. Land-Use and Land-Cover Change (LUCC): Implementation Strategy. A Core Project of the International Geosphere-Biosphere Program and the International Human Dimensions Program on Environmental Change. IGBP Report 48, IHDP Report 10, Stockholm, 1999. 125 p. Disponível em: <http://www.ihdp.uni-bonn.de/ html/publications/reports/report10/luccisindex.htm>. Acesso em: 07 ago. 2013.

MARTINELLI, M. Mapas, gráficos e redes: elabore você mesmo. São Paulo: Oficina de textos, 2014.

NIR, D. Man, a geomorphologycal agent: an introduction to anthropic geomorphology. Jerusalém: Ketem Pub. House, 1983. 184p.

PASCHOAL, L. G.; CONCEIÇÃO, F. T.; CUNHA, C. M. L. Alterações hidrogeomorfológicas devido à dinâmica de uso da terra na Bacia Hidrográfica do Ribeirão Santa Gertrudes (SP). Revista Brasileira de Geociências, São Paulo, v. 42 (Supl. 1), p. 70 - 83. dez. 2012

RAMGRAB et al. Carta Geológica do Brasil ao Milionésimo, Sistemas de Informações Geográficas. Programa Geologia do Brasil. CPRM: Brasília, 2004. Disponível em: http://geobank.sa.cprm.gov.br/pls/publico/ geobank.download.downloadlayouts?p_webmap=N. Acesso em: 12 de novembro de 2013.

RODRIGUES, C. Morfologia Original e Morfologia Antropogênica na Definição de Unidades Espaciais de Planejamento Urbano: Exemplo na Metrópole Paulista. Revista do Departamento de Geografia, São Paulo, n. 17, p. 101 - 111. 2005.

ROSA, M. Geografia de Pelotas. Pelotas: EDUFPEL, 1986.

SILVA, P. F.; HECK, C. R.; SILVA, M.; SIMON, A. L. H. Utilização de anaglifos digitais tridimensionais no mapeamento geomorfológico de ambientes lagunares. In: SIMPÓSIO BRASILEIRO DE GEOGRAFIA FÍSICA APLICADA, 15, 2013. Vitória. Anais...Vitória: Universidade Federal do Espírito Santo, 2013. p. 184-191. 1 CD. 
SILVEIRA, A.; CUNHA, C.M. L. Cartografia Geomorfológica como subsídio para a análise das interferências do uso da terra no desencadeamento dos processos erosivos: um estudo em área canavieira. RA'E GA, Curitiba, v. 21, p. 365 - 391. 2010.

SIMON, A. L. H. A dinâmica do uso da terra e sua interferência na morfohidrografia da bacia do Arroio Santa Bárbara - Pelotas (RS). 2007,185 p. Dissertação (Mestrado em Geografia), IGCE/UNESP, Rio Claro, 2007.

SOUZA, T. A. Avaliação da potencialidade de imagens tridimensionais em meio digital para o mapeamento geomorfológico. Revista Geonorte, Manaus, v. 2, n. 4, p.1348 - 1355, (Edição Especial). 2012.

SUERTEGARAY, D. M. A. NUNES, J. O. R. A natureza da Geografia Física na Geografia. Revista Terra Livre, São Paulo, n. 17, p. 11-24, 2001.

SZABÓ, J; DÁVID, L.; LÓCZY, D. Anthropogenic Geomorphology: a guide to manmade landforms. London: Springer, 2010. 250 p.

III Plano Diretor de Pelotas 2008 (III PDP) Disponível em: http://www.pelotas.rs.gov.br/ politica_urbana_ambiental/planejamento_urbano/III_plano_diretor/default.htm. Acesso em: 17 de outubro de 2014

ZANATTA, F. A. S.; LUPINACCI, C. M.; BOIN, M. N. O uso da terra e as alterações no relevo na alta bacia do Ribeirão Areia Dourada, Marabá Paulista (SP): um estudo a partir de princípios da Antropogeomorfologia. Revista Brasileira de Geomorfologia, São Paulo, v. 16, n. 1, p. 3 - 17, (jan-mar). 2015.

Recebido em dezembro de 2015

Aceito em agosto de 2016 